\title{
RESEARCH
}

Open Access

\section{Systemic translocation of Staphylococcus drives autoantibody production in HIV disease}

Zhenwu Luo ${ }^{1}$, Min Li ${ }^{1}$, Yongxia Wu' ${ }^{1}$, Zhefeng Meng ${ }^{2}$, Lisa Martin³ ${ }^{3}$ Lumin Zhang ${ }^{4}$, Elizabeth Ogunrinde ${ }^{1}$,

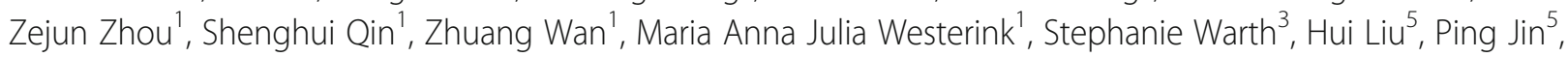
David Stroncek ${ }^{5}$, Quan-Zhen Li', Ena Wang ${ }^{7}$, Xueling Wu ${ }^{8}$, Sonya L. Heath ${ }^{9}$, Zihai Li', Alexander V. Alekseyenko ${ }^{10}$ and Wei Jiang ${ }^{1,3^{*}}$ (D)

\begin{abstract}
Background: Increased autoreactive antibodies have been reported in HIV disease; however, the mechanism accounting for autoantibody induction in HIV remains unknown.

Results: Herein, we show that seasonal influenza vaccination induces autoantibody production (e.g., IgG antinuclear antibody (ANA) and anti-double-stranded DNA antibody (anti-dsDNA)) in some viral-suppressed antiretroviral therapy (ART)-treated HIV+ subjects, but not in healthy controls. These autoantibodies were not derived from antigen-specific B cells but from activated "bystander" B cells analyzed by single-cell assay and by study of purified polyclonal ANAs from plasma. To explore the mechanism of autoantibody generation in HIV+ subjects, plasma level of microbial products, gene expression profile of B cells, and B cell receptor (BCR) repertoires were analyzed. We found that autoantibody production was associated with increased plasma level of microbial translocation; the patients with high autoantibodies had skewed B cell repertoires and upregulation of genes related to innate immune activation in response to microbial translocation. By analyzing circulating microbial $16 \mathrm{~S}$ rDNA in plasma, the relative abundance of Staphylococcus was found to be associated with autoantibody production in HIV+ subjects. Finally, we found that injection of heat-killed Staphylococcus aureus promoted germinal center B cell responses and autoantibody production in mice, consistent with the notion that autoantibody production in HIV+ patients is triggered by microbial products.
\end{abstract}

Conclusions: Our results showed that translocation of Staphylococcus can promote B cell activation through enhancing germinal center response and induces autoantibody production. It uncovers a potential mechanism linking microbial translocation and autoimmunity in HIV+ disease and provides a strong rationale for targeting Staphylococcus to prevent autoantibody production.

Keywords: Autoantibodies, Staphylococcus, Plasma microbial 165 rDNA

\footnotetext{
* Correspondence: jianw@musc.edu

'Department of Microbiology and Immunology, Medical University of South

Carolina, 173 Ashley Ave. BSB208D, Charleston, SC 29425, USA

${ }^{3}$ Division of Infectious Diseases, Department of Medicine, Medical University

of South Carolina, Charleston, SC 29425, USA

Full list of author information is available at the end of the article
}

(c) The Author(s). 2019 Open Access This article is distributed under the terms of the Creative Commons Attribution 4.0 International License (http://creativecommons.org/licenses/by/4.0/), which permits unrestricted use, distribution, and reproduction in any medium, provided you give appropriate credit to the original author(s) and the source, provide a link to the Creative Commons license, and indicate if changes were made. The Creative Commons Public Domain Dedication waiver (http://creativecommons.org/publicdomain/zero/1.0/) applies to the data made available in this article, unless otherwise stated. 


\section{Introduction}

In healthy people, most autoreactive B cells are effectively removed from the germinal center (GC), and only a small portion of self-reactive GC B cells can escape from deletion [1]. In HIV+ individuals, many autoantibodies are reported and autoimmune diseases occur during immunological recovery after antiretroviral therapy (ART) [2-4]. ART treatment significantly controls viral replication, decreases chronic immune activation, and partially recovers intestinal mucosal integrity in HIV disease [5]. ART-treated patients suffer from autoimmune symptoms associated with increased levels of B cell activation, pathologic autoantibodies, and residual systemic microbial translocation $[6,7]$.

Although many pathophysiologic hypotheses have been posited on the synthesis of autoantibodies, such as a direct role of viral particles, molecular mimicry, immune complex, polyclonal B lymphocyte activation, and dysregulation of $\mathrm{B} / \mathrm{T}$ lymphocyte interaction [8-11], how autoantibody is produced during immunological recovery under ART remains unknown. In ART-treated HIV+ subjects, the immune responses (e.g., CD4+ T cell function) mostly recover, but the humoral immune system is subject to repeated and long-term stimulation through systemic bacterial products (e.g., LPS) [12]. Microbial translocation has been linked to HIV-associated B cell hyperactivation and perturbation [13]. Toll-like receptor (TLR) ligands play a role in B cell perturbation, autoantibody production, and autoimmune diseases [14-18]. In the current study, we found autoantibodies were induced in response to influenza vaccination in some viral-suppressed ART-treated $\mathrm{HIV}+$ individuals. Moreover, vaccine-mediated autoantibody production was associated with baseline increased plasma level of microbial translocation and relative enrichment of translocation of Staphylococcus in HIV+ subjects but not in healthy controls. Furthermore, GC B cell activation and autoantibody induction were observed in C57BL/ 6 mice after intraperitoneal injection of heat-killed Staphylococcus aureus.

\section{Materials and methods}

\section{Study subjects}

In the current study, 16 healthy controls and 26 aviremic ART-treated HIV+ subjects were included. HIV-infected subjects were on viral-suppressive ART for at least 2 years. Inclusion criteria were as follows: (1) men and women age 18 or older, (2) be able and willing to provide informed consent, (3) healthy control individuals have self-reports of HIV-negative, and (4) HIV+ individuals have been treated with ART and have plasma HIV RNA below the limit of detection for at least 24 weeks (a single blip to $\leq$ 500 copies/mL will be allowed). Exclusion criteria were as follows: (1) pregnancy or breast-feeding by self-report; (2) recent severe illness such as anemia; (3) need for or use of specific medications during the 120 days prior to enrollment: antibiotics, systemic immunomodulatory agents, and supraphysiologic doses of steroids (> $10 \mathrm{mg} /$ day); and (4) any other condition that the investigator judge makes the subject unsuitable for the study or unable to comply with the study requirements. The clinical characteristics of patients are shown in Additional file 1: Table S1. Participants received a single intramuscular dose of inactivated trivalent vaccine (2013-2014, Fluvirin, GSK, Philadelphia, PA), containing $15 \mu \mathrm{g}$ influenza hemagglutinin (HA) of each strain of A/Christchurch/16/2010 (H1N1), A/Texas/ 50/2012 (H3N2), and B/Massachusetts/2/2012. This study was approved by the Medical University of South Carolina (Pro00020606).

\section{Mice}

C57BL/6 mice were purchased from the Jackson Laboratories and housed at the Medical University of South Carolina. All animal studies were approved by the Institutional Animal Care and Use Committee (IACUC) at the Medical University of South Carolina. Mice were injected with PBS, heat-killed Salmonella typhimurium (HKST, InvivoGen, San Diego, CA), heat-killed Pseudomonas aeruginosa (HKPA, InvivoGen), or heat-killed Staphylococcus aureus (HKSA, InvivoGen) twice a week for 4 weeks and then once a week for 8 weeks by intraperitoneal (i.p.) route. The heat-killed bacteria were given $5 \times 10^{7} /$ mice/time.

\section{Flow cytometric analysis of cells from mice}

Mononuclear cells were obtained from mouse spleen or lymph nodes by physical digestion and straining through a $70-\mu \mathrm{m}$ filter, and stained for surface markers and intracellular cytokines using standard flow cytometric protocols. The following antibodies were used for cell staining: anti-CD3-PerCP-Cy5.5 (17A2), anti-CD4-BV510 (RM4-5), anti-CD8a-APC-vio770 (53-6.7), anti-CD44-FITC (IM7), anti-CD62L-BV421 (MEL-14), anti-CD25-PE-vio770 (7D4), anti-CD69-PE (H1.2F3), anti-IL-17A-PE (TC11-18H10), anti-IL-22-APC (IL22JOP), anti-IFN- $\gamma$-PE-Cy7 (XMG1.2), anti-CD19-BV421 (1D3), anti-B220-PerCP-cy5.5 (RA3-6 B2), anti-GL7-PE (GL7), anti-CD95-PE-vio770 (REA453), anti-CD86-APC-vio770 (PO3.3), goat anti-mouse IgG-FI TC, and anti-IgM-BV510 (R6-60.2). For anti-IFN- $\gamma$ staining, cells were stimulated in complete RPMI-1640 + 10\% FBS with leukocyte activation cocktail (BD, San Jose, CA) at $2 \mu \mathrm{L} / \mathrm{mL}$. After being cultured at $37^{\circ} \mathrm{C}$ for $4 \mathrm{~h}$, cells were collected and washed with PBS. Fifty microliters of aqua blue (Life Technologies, Carlsbad, CA) was used at $4{ }^{\circ} \mathrm{C}$ for $20 \mathrm{~min}$ to exclude dead cells, then surface markers and intracellular cytokines were used by standard flow cytometric protocols. Cells were collected in a BD FACSVerse flow cytometer (BD, San Jose, CA), and data were analyzed by FlowJo software (version 10.0.8). 


\section{Flow cytometric analysis of cells from human}

Plasma was separated from EDTA-contained fresh blood samples, aliquoted, and stored at $-80^{\circ} \mathrm{C}$. Peripheral blood mononuclear cells (PBMCs) were isolated over a Ficoll-Paque cushion (GE Healthcare, Wauwatosa, WI). PBMCs were used for annexin V assays. Blood samples were used for all other flow cytometry-based assays except annexin $V$ assays. For surface staining, antibodies were incubated with blood or PBMCs at room temperature for 15 min. After surface staining in blood samples, red cells were lysed, washed, and analyzed by flow cytometry. The fluorochrome-labeled mAbs (BD Pharmingen, San Jose, CA) used for flow cytometry included the following: anti-human CD3 (OKT3), anti-human CD4 (RPA-T4), anti-human CD8 (RPA-T8), anti-human CD19 (HIB19), anti-human CD20 (L27), anti-human CD27 (M-T271), anti-human CD38 (HIT2), anti-human CD45RA (HI100), anti-human HLA-DR (G46-6), anti-human ki67 (B56), anti-human IgD (IA6-2), anti-human IgG (G18-145), isotype control antibodies (BD Pharmingen), and annexin $\mathrm{V}$ (BD Pharmingen). Cells were collected in a BD FACSVerse flow cytometer (BD, San Jose, CA), and data was analyzed by FlowJo software (Version 10.0.8).

\section{ANA and anti-dsDNA antibody detection}

Plasma levels of anti-dsDNA IgG and IgM were quantified using a commercial kit according to the manufacturer's protocol (Immuno-Biological Laboratories, Minneapolis, $\mathrm{MN}$ ). Antinuclear antibody (ANA) IgG detection was performed in plasma by ELISA using Hep-2 laryngeal carcinoma cell lysates as the coating antigens (ATCC, Manassas, VA).

\section{Sorting of antigen-specific single B cells by flow cytometry}

The method of antigen-specific single B cell sorting was described in a previous study [19]. In the current study, 80$200 \mathrm{bp}$ dsDNAs from calf thymus were purified by gel electrophoresis and biotinylated according to the manufacturer's protocol (VECTOR, Burlingame, CA). Biotinylated dsDNA was confirmed by ELISA. Fifty microliters of aqua blue was used to exclude dead cells in about 25 million PBMCs on D14 post-vaccination. Next, $50-\mu \mathrm{L}$ antibody cocktail containing anti-CD3-PerCP (OKT3), anti-CD14-APC-cy7 (HCD14), anti-CD19-BV421 (HIB19), anti-CD20-PE-cy7 (L27), anti -IgM-APC (G20-127), anti-IgG-PE (G18-145), and 15- $\mu \mathrm{L}$ biotinylated dsDNA $(130 \mathrm{ng} / \mu \mathrm{L})$ was surface stained for $1 \mathrm{~h}$ at $4{ }^{\circ} \mathrm{C}$. To sort hemagglutinin (HA)-specific single B cells, $10 \mu \mathrm{L}$ biotinylated HA (200 ng/ $\mu \mathrm{L}$, Emory University) was used. After three times washings with PBS, $50 \mu \mathrm{L}$ of 1:1000 diluted streptavidin-FITC (BD Pharmingen) was added and incubated for $15 \mathrm{~min}$ at $4{ }^{\circ} \mathrm{C}$. Antigen-specific IgG+ single B cells (CD3-CD14-CD19+CD20+IgG+ dsDNA+ or HA+) were identified and sorted into a 96-well PCR plate containing $10 \mu \mathrm{L}$ of catching buffer per well using FACS Aria II cell sorter (BD Biosciences, San Jose, CA). The catching buffer contained $2 \mu \mathrm{L}$ of $10 \times$ first strand buffer (Invitrogen, Carlsbad, CA), $2 \mu \mathrm{L}$ of $0.1 \mathrm{M}$ DTT (Invitrogen), $1 \mu \mathrm{L}$ of RNase Out (Invitrogen), and $0.05 \mu \mathrm{l}$ of igepal (Sigma-Aldrich, St. Louis, MO). The sorted cells were stored at $-80^{\circ} \mathrm{C}$ for future uses, and flow cytometry data was analyzed by Flowjo software (Version 10.0.8).

\section{Single B cell immunoglobulin gene amplification and antibody expression}

As described in previous studies [20], the frozen plates with sorted dsDNA-specific single B cells were thawed at room temperature, and reverse transcription was carried out by adding $3 \mu \mathrm{L}$ of $50 \mu \mathrm{M}$ random hexamers (Invitrogen), $1 \mu \mathrm{L}$ of $10 \mathrm{mM}$ dNTP mix (Invitrogen), and $1 \mu \mathrm{L}$ of SuperScript III (Invitrogen) into each well. The mixture was incubated at $25^{\circ} \mathrm{C}$ for $10 \mathrm{~min}, 50^{\circ} \mathrm{C}$ for $50 \mathrm{~min}$, and $85^{\circ} \mathrm{C}$ for $5 \mathrm{~min}$. $\mathrm{IgH}$, Igא, and Ig $\lambda$ genes were amplified from cDNA. All PCRs were performed in 96-well PCR plates in a total volume of $25 \mu \mathrm{L}$ containing $5 \mu \mathrm{L}$ of $5 \times$ HotStar HiFidelity PCR buffer, $1 \mu \mathrm{L}$ of primer $(20 \mu \mathrm{M})$, and $0.25 \mu \mathrm{L}$ of HotStar HiFidelity Polymerase (Qiagen). Each round of PCR was initiated at $94{ }^{\circ} \mathrm{C}$ for $5 \mathrm{~min}$, followed by 40 cycles of $94^{\circ} \mathrm{C}$ for $30 \mathrm{~s}, 58^{\circ} \mathrm{C} 60 \mathrm{~s}$, and $72^{\circ} \mathrm{C}$ for $1 \mathrm{~min}$, followed by $72^{\circ} \mathrm{C}$ for $10 \mathrm{~min}$. The positive products were selected for direct sequencing or subsequently cloned into the corresponding expression vectors as previously described [21]. The recombinant plasmids were co-transfected into $293 \mathrm{~T}$ cells with equal amounts of paired heavy and light chains using Lipofectamine 3000 (Invitrogen). The full length of IgGs was expressed and purified using Protein A/G Agarose (ThermoFisher, Waltham, MA).

\section{ANA immunofluorescence}

ANA immunofluorescence was analyzed following the manufacturer's protocol (MBL, Des Plaines, IL). Briefly, Hep-2-coated slides were incubated with $25 \mu \mathrm{L}$ of 1:40 diluted plasma for $30 \mathrm{~min}$ in a moist chamber at room temperature, then washed with PBS and incubated with $30-\mu \mathrm{L}$ FITC-labeled goat anti-human IgG for $30 \mathrm{~min}$. ANA-negative and ANA-positive controls were included in all experiments. After washing with PBS, samples were examined with a confocal microscope (Olympus BX61). The staining of patient samples was determined by comparison with the controls at equal exposure times.

\section{ELISA development for detection of antibodies against lipoteichoic acid of Staphylococcus aureus}

Purified lipoteichoic acid (LTA) from Staphylococcus aureus (InvivoGen) was diluted at the concentration of $4 \mu \mathrm{g} /$ $\mathrm{mL}$ in coating buffer (KPL, Milford, MA) and added to microtiter wells. The plate was incubated at $4{ }^{\circ} \mathrm{C}$ overnight. Microwells were washed three times with phosphate buffered saline wash buffer (PBS with $0.1 \%$ Tween 
20) and blocked with PBS containing 3\% bovine serum albumin (BSA) for $120 \mathrm{~min}$ at $37^{\circ} \mathrm{C}$. Plasma was diluted 1:50 for IgA anti-LTA antibody detection and 1:5000 for IgG anti-LTA antibody detection in PBS containing 3\% BSA, and $100 \mu \mathrm{L}$ of the dilution was added to each well. The plate was incubated at room temperature for $60 \mathrm{~min}$ with rotation at $450 \mathrm{rpm}$. Horseradish peroxidase (HRP)-labeled goat anti-human IgA or IgG was added to make a 1:2500 dilution in PBS containing 3\% BSA. The plate was then incubated for $60 \mathrm{~min}$ at room temperature. After washing, $100 \mu \mathrm{L} 2$ 2, 2' -azino-di (3-ethylbenzothiazoline-6-sulfonate) (ABTS) was added and incubated for 30 $\mathrm{min}$, and finally, 405-nm emission was read within $30 \mathrm{~min}$.

\section{Affinity purification of ANA from plasma}

Antibodies were purified in plasmas of human subjects. Briefly, ANA IgG or IgM from the plasmas of HIV+ subjects was purified using NHS Mag Sepharose (GE Healthcare). Buffer of Hep-2 laryngeal carcinoma cell lysates (ATCC) was exchanged to PBS using ultra centrifugal filters (Amicon, EMD Millipore, Massachusetts), then covalently coupled to NHS magnetic beads. Plasma samples and binding buffer were mixed at a $1: 1$ ratio and incubated at $4{ }^{\circ} \mathrm{C}$ for $4 \mathrm{~h}$ in a column with ANA antigens immobilized on magnetic beads. The unbound fraction was removed, and the column was washed extensively with $50 \mathrm{mM}$ Tris/150 $\mathrm{mM} \mathrm{NaCl}$. ANA was eluted sequentially with $0.1 \mathrm{M}$ glycine/ $\mathrm{HCl}$ buffer at $\mathrm{pH} 2.9$ and concentrated using ultra centrifugal filters (Amicon, EMD Millipore, Massachusetts).

\section{Competitive ELISA}

Hep-2 laryngeal carcinoma cell lysates (ATCC) were diluted in PBS and added to microtiter wells at $4{ }^{\circ} \mathrm{C}$ overnight. Microwells were then washed three times with PBS wash buffer $(0.1 \%$ Tween 20$)$. The reaction was blocked using blocking buffer (KPL, Milford, MA) for $120 \mathrm{~min}$ at $37^{\circ} \mathrm{C}$. Purified ANAs were diluted two times from 1:10. The antibody solution was incubated with influenza vaccine antigen at 1:1 ratio for $30 \mathrm{~min}$ at room temperature. Antibody solution in PBS at 1:1 ratio was used as a control. One hundred microliters of the reaction mixture was added to the wells coated with antigens and incubated at room temperature for $1 \mathrm{~h}$. After washing for three times, goat anti-human IgM/IgG-conjugated HRP was added at a 1:5000 dilution in PBS containing 3\% BSA and incubated for $60 \mathrm{~min}$ at room temperature. HRP-Streptavidin was added at a 1:1000 dilution in PBS containing 3\% BSA, and then incubated for 30 min at room temperature. After washing, $100 \mu \mathrm{L}$ ABTS was added and incubated for $30 \mathrm{~min}$, and the plate was read at $405 \mathrm{~nm}$ emission within $30 \mathrm{~min}$.

\section{Autoantigen microarray}

Autoantigen microarrays were performed by Genomics and Microarray Core at the University of Texas Southwestern
Medical Center. IgG autoantibodies from plasma were analyzed using 125-plex autoantigen arrays. Plasma samples were treated with DNase I, diluted to 1:50, and incubated with autoantigen arrays. Cy3-labeled anti-IgG was used to detect IgG autoantibodies, and the arrays were scanned with a GenePix $4400 \mathrm{~A}$ Microarray Scanner. The images were analyzed using GenePix 7.0 software. The averaged net fluorescent intensity of each autoantigen was normalized to internal controls, and scaling and centering $(x-\operatorname{mean}(x)) / \operatorname{sd}(x)$ were performed after $\log _{10}$ transformation.

\section{Plasma LPS level}

Plasma LPS levels were measured by endpoint chromogenic limulus amebocyte lysate assays kit (Lonza, Basel, Switzerland) according to the manufacturer's protocol. Samples were 1:10 diluted with endotoxin-free water and subsequently heated to $85^{\circ} \mathrm{C}$ for 15 min to inactivate inhibitory proteins. Background was subtracted, and LPS levels were calculated based on standards.

\section{Gene expression analysis by microarray}

In the current study, total B cells (purity $>97 \%$ ) were isolated in PBMCs using B cell isolation kit (Miltenyi Biotec, Bergisch Gladbach, Germany). Total RNA from B cells was extracted using RNeasy Micro kit following the manufacturer's protocol (Qiagen, Valencia, CA), quantified by Nanodrop 2000 (Nanodrop, Wilmington, DE), and qualified by Agilent 2100 Bioanalyzer (Agilent Technologies, Santa Clara, CA). RNA concentration more than $20 \mathrm{ng} / \mu \mathrm{L}$ was selected to perform Affymetrix GeneChip assays, including high ANA HIV+ subjects $(n=5)$ and low ANA HIV+ subjects $(n=9)$ on D0 and D7 post-vaccination. Affymetrix Human GeneChip U133 Plus 2.0 Array was used for RNA hybridization and labeling assay according to the manufacturer's protocol (Affymetrix). The scanned images and probe signals were analyzed by GCOS (Affymetrix). All microarray data and statistical analyses were performed using R (version 3.3.1). Normalization was performed with RMA algorithm which included background adjustment and quantile normalization [22]. Selection of distinct gene expression was identified by $P$ value less than 0.05 . Biological profiles of distinct genes were analyzed and clustered using iPathway (Advaita, Plymouth, MI). All microarray data are available in the GEO database.

\section{Next-generation sequencing of the IGH repertoire}

Next-generation sequencing (NGS) of the B cells receptor (BCR) repertoire was described in a previous study [19]. RT-PCR reactions were conducted using a set of nested sequence-specific primers covering the variable $(\mathrm{V})$ and constant $(\mathrm{C})$ regions. Illumina paired-end sequencing communal primer $\mathrm{B}$ was linked to each inside $\mathrm{V}$ region primer. Illumina paired-end sequencing communal primer A and a barcode sequence were linked to the reverse inside C-beta 
primer. cDNA was reverse transcribed from the total RNA samples using a mixture of forward V-beta and reverse C-beta primers and reagents from the RT-PCR kit (Qiagen). After the first round of amplification, the PCR products were purified using AMPure XP beads (Beckman Coulter, Indianapolis IN). The second-round PCR was performed using a set of communal primers that completed the Illumina adaptor sequences. Final products were purified and quantified by Nanodrop 2000, pooled in equimolar proportions, and followed by $300 \mathrm{bp}$ paired-end sequencing on the Illumina MiSeq platform. Raw high-throughput sequencing reads were quality controlled, assembled, and filtered using pRESTO [23]. V(D)J germline segments were assigned using IMGT/HighV-QUEST (http://www.imgt.org/). Clonal clustering was performed using Change-O [24]. Clone abundance, diversity, and amino acid property were analyzed as described in previous studies [25]. Custom statistical analysis and plots were assessed and shown by R.

\section{Plasma circulating microbial 165 rDNA}

Method of plasma 16S rDNA analysis was described in a previous study [26]. In the current study, bacterial DNA was extracted from $400 \mu \mathrm{L}$ of plasma or endotoxin-free water controls using QIAamp UCP Pathogen Mini Kit according to the manufacturer's instructions (Qiagen). To prevent batch-to-batch variation, all samples were sequenced at the same time. V4 variable region of bacterial 16S rDNA gene was amplified using PCR primers 515/806 in HotStarTaq Plus Master Mix (Qiagen) under the following conditions: $94^{\circ} \mathrm{C}$ for $3 \mathrm{~min}$, followed by 28 cycles of $94^{\circ}$ $\mathrm{C}$ for $30 \mathrm{~s}, 53^{\circ} \mathrm{C}$ for $40 \mathrm{~s}$, and $72^{\circ} \mathrm{C}$ for $1 \mathrm{~min}$, and a final elongation step at $72{ }^{\circ} \mathrm{C}$ for $5 \mathrm{~min}$. Sequencing was performed at MR DNA on an Ion Torrent PGM following the manufacturer's guidelines (Shallowater, TX, USA). Sequencing data was processed using a proprietary analysis pipeline (MR DNA). Briefly, sequences were depleted of barcodes and primers, short sequences less than $200 \mathrm{bp}$ were removed, and sequences with ambiguous base calls and homopolymer runs exceeding $6 \mathrm{bp}$ were also removed. Sequences were denoised and operational taxonomic units (OTUs) were defined clustering at 3\% divergence (97\% similarity) followed by removal of singleton sequences and chimeras. Final OTUs were taxonomically classified using BLASTn against a database derived from RDPII and NCBI (www.ncbi.nlm.nih.gov).

OTU tables and different levels of taxonomic tables were imported to $\mathrm{R}$ for statistical analysis. To remove potential bacterial $16 \mathrm{~S}$ rDNA contamination from molecular biological reagents, we removed genera from experimental samples at the OTU-level if they were detected in the water controls. To measure the richness and evenness of a plasma microbiome community, Simpson index of diversity was calculated using Vegan package to measure $\alpha$-diversity of each sample. ANCOVA model was used to assess the associations with Simpson diversity index, clinical and demographic characters, and levels of autoreactive antibody. The Bray-Curtis coefficient was calculated using the Vegan package to evaluate $\beta$-diversity and compositional dissimilarity among the microbial community. The relationship between $\beta$-diversity and autoreactive antibodies was assessed using permutational multivariate analysis of variance (PERMANOVA).

\section{Statistical analysis}

Conventional measurements of central location and dispersion were used to describe the data, and differences in continuous measurements between groups were compared by non-parametric Mann-Whitney's $U$ tests. To explore associations between pairs of continuous variables, Spearman's rank correlation was used. Comparison analysis was performed using R (version 3.3.1) or GraphPad Prism 6. All tests were two-sided, and $P \leq 0.05$ was considered to denote statistical significance.

\section{Results}

Autoantibodies induced by seasonal influenza vaccination in HIV+ subjects

Following immunization with the 2013-2014 seasonal influenza vaccine in 16 healthy controls and 26 ART aviremic HIV-infected subjects (Additional file 1: Table S1), we found that the IgG ANAs were increased in HIV+ subjects $(P<0.0001)$, but there was no change in healthy controls $(P=0.53)$ (Fig. 1a). To identify if other autoantibodies besides ANA were generated after immunization, we measured plasma IgG anti-dsDNA antibody, a pathologic autoantibody in systemic lupus erythematosus (SLE) [27]. Indeed, IgG anti-dsDNA antibodies showed the same pattern as IgG ANAs. After immunization, plasma IgG anti-dsDNA antibody levels were significantly increased in HIV-infected subjects $(P=0.0002)$, but not in healthy controls $(P>0.99)$ (Fig. 1b). Next, we examined the overall profile of autoantibodies using an autoantigen array containing 125 self-antigens that have previously been shown to induce autoantibodies [28]. HIV-infected subjects were stratified to high ANA (fold change of ANA on D14/D0 $\geq 2$ ) ( $n$ $=12$ ) and low ANA (fold change of ANA on D14/D0 $<2$ ) $(n=14)$ groups. Consistent with the results from ANA and anti-dsDNA antibodies, the universal autoantibodies did not change in healthy controls on D14; however, the autoantibodies against a wide spectrum of autoantigens were significantly increased in response to influenza vaccination in HIV+ subjects on D14 (Fig. 1c).

\section{Autoantibodies generated from bystander B cell activation}

To investigate the source of autoreactive antibodies induced by influenza vaccination, we purified ANA polyclonal 


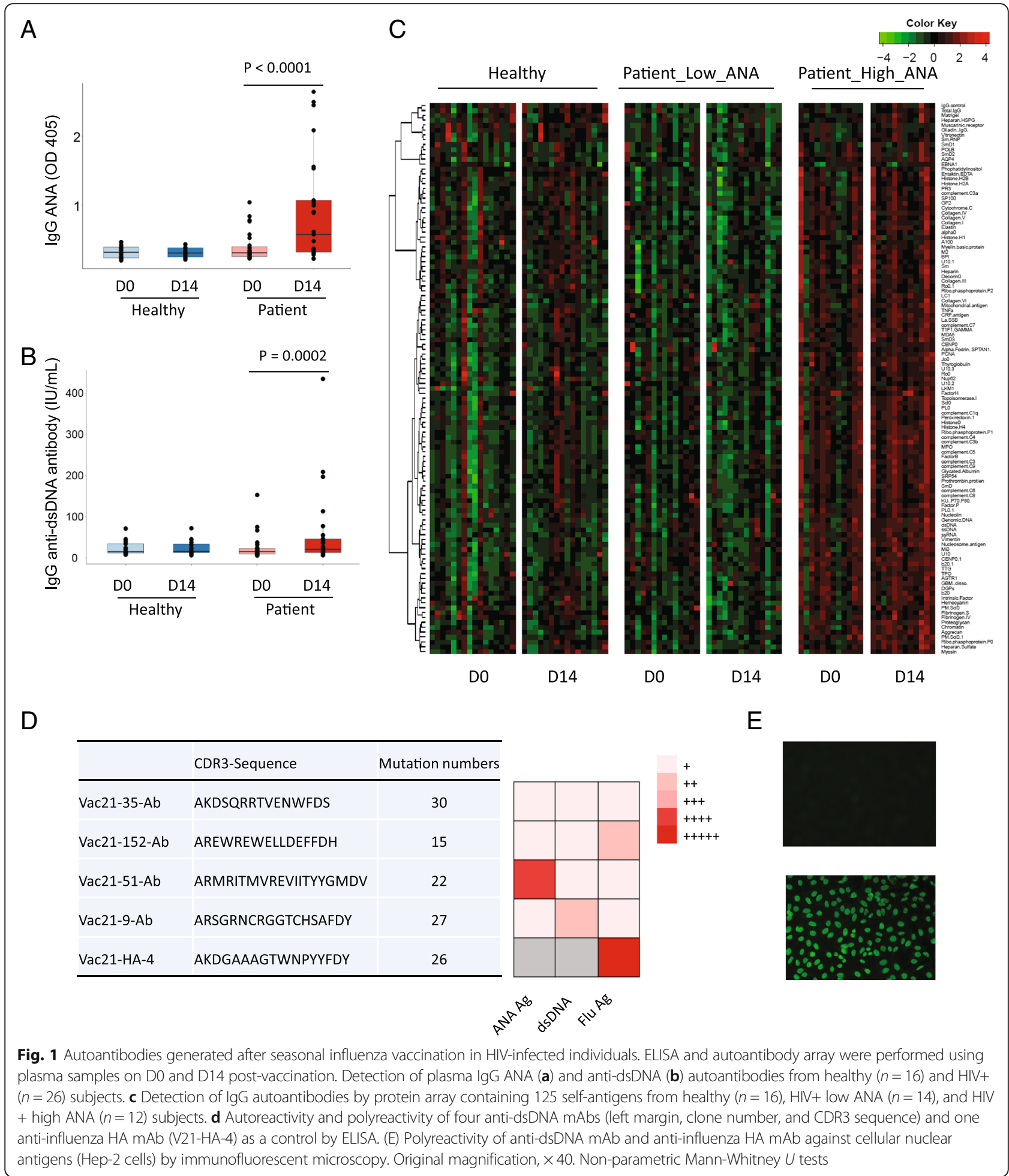

antibodies from plasmas of HIV+ high ANA subjects and examined their binding abilities to nuclear antigens in the presence of influenza antigens by competitive ELISA. Little cross-reactivity was observed in IgG ANAs with influenza antigens (Additional file 1: Figure S1A). Similar to IgG ANA, the majority of IgM ANAs were not cross-reactive to influenza antigens (Additional file 1: Figure S1B). We also sorted dsDNA+IgG+ B cells from an HIV+ subject who had more than fourfold induction of IgG anti-dsDNA (D14/D0) (Additional file 1: Figure S1C). Two hundred twenty-six single dsDNA-specific IgG+ B cells were sorted. Heavy or light chains were successfully amplified from 147 
single B cells. Eighty-nine recombinant monoclonal antibodies (mAbs) were generated from heavy chains with paired light chains, and 31 of those mAbs displayed substantial reactivity to dsDNA antigens. The average number of mutations per sequence among anti-dsDNA mAb was 16.4 (Additional file 1: Table S2). None of these mAbs was clonally related. Only four of them (12.9\%) showed low-affinity cross-reactivity to influenza vaccine antigens (Fig. 1d), and the average number of mutations per sequence among these four mAbs was 23.5. We further measured the reactivity of these four anti-dsDNA mAbs with Hep-2 cell lysates, and with one mAb from influenza hemagglutinin (HA)-specific IgG+ B cells in the same donor set as a control, all of those four mAbs showed cross-reactivity (Fig. 1d, e, Additional file 1: Table S2). After the IgH and IgL chain genes of those polyreactive four mAbs were reverted back to their germline form, all four mAbs lost reactivity to dsDNA antigens and influenza vaccine antigens. These results suggest that those four out of 31 anti-dsDNA mAbs were from the non-reactive precursors, and the other vaccine-mediated autoantibodies were not generated via molecular mimicry of similar epitopes of influenza antigen or via polyreactivity of influenza-specific $\mathrm{B}$ cells. Thus, the autoantibodies should be generated independently with influenza antigen-specific antibodies, but from bystander B cells activation [11].

\section{Systemic microbial translocation was associated with ANA production in HIV+ subjects}

To determine the mechanism of autoantibody generation in HIV+ subjects, RNA was isolated from purified total B cells and analyzed by microarray. Gene expression was shown after normalization (Additional file 1: Figure S2). Relative transcript abundance was shown as the ratio of gene expression from HIV+ high ANA group vs low ANA group (Fig. 2a). To better quantify this gene variation in a functional context, the biological pathways that associated with gene expression were characterized. A selected list of biological pathways with enriched transcripts was shown to reflect the significant differences between the two HIV+ groups (Fig. 2b).

The reduced gene expression of endocytosis and phagosome pathway in HIV+ high ANA subjects was compared to low ANA subjects, suggesting a decreased clearance of apoptotic debris along with immune complexes [29, 30]. Notably, HIV+ high ANA group showed decreased gene expression that related to focal adhesions, gap junction, adherens junction, and tight junction compared to those in low ANA group (Fig. 2b, c). The B cell transcriptome alterations may be the downstream of impaired mucosal barriers but need further investigation. In contrast, genes related to the TLR signaling pathway such as TLR1, TLR2, TLR4, and MyD88 were highly expressed in the HIV+ high ANA group compared to low ANA group (Fig. 2b, c).
These TLR-associated genes play a role in sensing translocated microbial products and producing pro-inflammatory cytokines [31]. Similarly, IL-1 $\beta$, IFN- $\alpha$, and IL-8, which are downstream cytokines of TLR signaling pathway, were highly expressed in the HIV+ high ANA group compared to low ANA group (Fig. 2c). These results suggest that microbial translocation-related innate immune activation is associated with autoantibody production in response to influenza vaccination in HIV disease.

\section{Systemic microbial translocation and distinct B cell repertoire profiles in autoantibody induction in HIV+ subjects}

The results of B cell gene expression profiles by microarray indicate that microbial translocation may play a critical role in the generation of autoantibodies in ART-treated HIV disease. We therefore examined plasma LPS level, a marker of systemic microbial translocation, among the three study groups. Elevated plasma LPS level was observed in HIV+ high ANA group compared to the other two groups (Fig. 3a). Importantly, plasma LPS level at baseline was positively correlated with both IgG ANA $(r=0.49, P=$ $0.014)$ and IgG anti-dsDNA $(r=0.44, P=0.029)$ levels after immunization (Additional file 1: Figure S3A, D14/D0). To establish evidence for direct chronic LPS stimulation, we measured plasma soluble CD14 (sCD14), which secreted by CD14+ monocyte/macrophages and can bind LPS, and plasma LPS binding protein (LBP), which is produced by gastrointestinal and hepatic epithelial cells in response to LPS stimulation. The results showed higher levels of plasma sCD14 in HIV+ high ANA group compared to the other two groups (Fig. 3a), but no difference of plasma LBP was observed (Additional file 1: Figure S3B).

TLR activation has been shown to promote clonal expansion of autoreactive cells via TLR/B cell receptor (BCR) signal transduction [32, 33]. BCR/TLR dual signals in mature $B$ cells can enhance $B$ cell activation and directly initiate humoral autoimmunity [34]. To test whether BCR repertoires are different between ANA low and ANA high HIV+ subjects, we performed high-throughput sequencing of heavy chain variable $(\mathrm{V})$, joining $(\mathrm{J})$, and diversity (D) gene segments (VDJ) using purified B cell RNA in three donors from each HIV+ group on D14 after immunization. Sequencing was obtained and analyzed in each subject. The overall diversity of total B cells had a lower general sequence diversity index (qD) [35] in HIV+ high ANA group compared to low ANA group (Fig. 3b). The contraction in diversity was shown in both the total number of clones $(\mathrm{q} \rightarrow 0)$ and clonal dominance $(\mathrm{q} \rightarrow \infty)$ (Fig. 3b). We then investigated BCR clonal diversity in each isotype separately, and the same pattern was observed (Additional file 1: Figure S3C). These results showed that B cells from HIV+ high ANA group have significantly more focused number of clones and indicated 
A

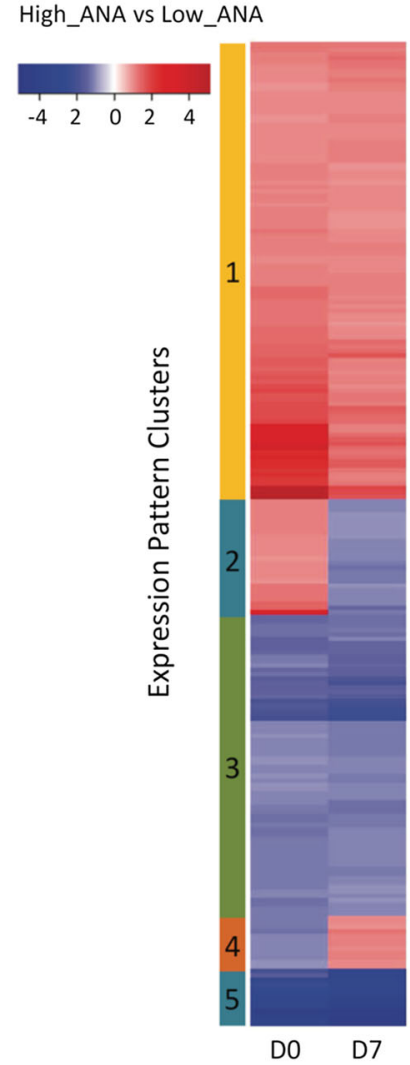

B High_ANA vs Low_ANA (DO)

\begin{tabular}{ll}
\hline Pathway name & p-value \\
Toll-like receptor signaling pathway & $3.61 \mathrm{E}-05$ \\
Systemic lupus erythematosus & $7.96 \mathrm{E}-05$ \\
Salmonella infection & $1.08 \mathrm{E}-04$ \\
Phagosome & $2.52 \mathrm{E}-04$ \\
NF-kappa B signaling pathway & $2.70 \mathrm{E}-04$ \\
Staphylococcus aureus infection & 0.006 \\
Natural killer cell mediated cytotoxicity & 0.007 \\
Inflammatory bowel disease (IBD) & 0.007 \\
Chemokine signaling pathway & 0.018 \\
RIG-I-like receptor signaling pathway & 0.018 \\
Fc gamma R-mediated phagocytosis & 0.03 \\
Endocytosis & 0.044 \\
\hline
\end{tabular}

High_ANA vs Low_ANA (D7)

\begin{tabular}{ll}
\hline Pathway name & $p$-value \\
Focal adhesion & $6.14 \mathrm{E}-06$ \\
Chemokine signaling pathway & 0.001 \\
Gap junction & 0.003 \\
Adherens junction & 0.006 \\
Endocytosis & 0.03 \\
Tight junction & 0.044 \\
\hline
\end{tabular}

\begin{tabular}{|c|c|c|c|c|}
\hline PTGS2 & TYROBP & CLEC7A & CSF1R & $\mathrm{HIST} 2 \mathrm{H} 4 \mathrm{~B}$ \\
\hline NCF2 & TLR8 & HIST2H3D & HIST1H3A & HIST1H4B \\
\hline CCR1 & IL8 & CSAR1 & CD14 & FPR1 \\
\hline HIST1H2BG & IL1B & CXCR1 & HIST1H2AD & HIST1H4D \\
\hline FPR2 & HIST1H2AJ & HIST1H2AK & FCAR & TLR2 \\
\hline TLR4 & HCK & CX3CR1 & CCL3L3 3 & TCF7L2 \\
\hline HIST1H2AM & SELPLG & ITK & HIST1H2AA & HLA-DQA2 \\
\hline $\mathrm{HIST} 2 \mathrm{H} 2 \mathrm{BF}$ & MYD88 & РАК1 & CTSS & PTPRM \\
\hline ATP6V1B2 & TLR1 & MAP3K2 & ITGA5 & МАРЗK8 \\
\hline BCL2A1 & HIST1H4J & FCGR3A & CDGIP & PTPRC \\
\hline TANK & LAMC2 & KIAA1033 & CTNND1 & MAP3K1 \\
\hline IFNAR2 & SPG21 & IL2RG & HCLS1 & $\mathrm{CD} 247$ \\
\hline TMEM173 & CTNNA3 & CYBB & ARF5 & ITGB2 \\
\hline STX7 & KIAA0196 & IFNGR2 & MAPK12 & SH3KBP1 \\
\hline PIK3R1 & IQGAP1 & VEGFA & STAM2 & GNG4 \\
\hline CALR & WASL & CCDC53 & ATM & CSNK2B \\
\hline ITCH & ITGA4 & LAMA3 & DOCK2 & RPS6KB1 \\
\hline EGFR & IFNA2 & IL12RB2 & PРP $3 C B$ & BLNK \\
\hline PAK2 & $C 4 B$ & FASLG & LBP & RRAS2 \\
\hline ZFYVE16 & IKBKB & PTEN & NTRK1 & CBLB \\
\hline PVRL3 & WASF1 & LY96 & & \\
\hline IL23A & TUBB2A & HIST1H4A & MYL12B & MPO \\
\hline CLDN24 & ARRB2 & HRAS & PRKCG & PRKACA \\
\hline MYLK2 & C6 & HTR2C & ARF6 & SH3GLB1 \\
\hline FN1 & MICB & DYNC1LI1 & TSG101 & ATP6V1G3 \\
\hline SNRPD3 & BIRC2 & RAB7A & $\mathrm{ADCY} 1$ & $\mathrm{HIST} 2 \mathrm{H} 2 \mathrm{AC}$ \\
\hline GRK4 & IFNA8 & РАK3 & RAB11FIP3 & GNB2 \\
\hline PIN1 & GRIN2A & CCND3 & RILP & IFNA17 \\
\hline TRADD & $\mathrm{IF|H1}$ & COL1A1 & MAVS & VWF \\
\hline C5 & NEDD4L & PPP3R1 & VEGFB & PLCG1 \\
\hline GNG7 & MYH7 & PSD3 & ROCK2 & MYHO \\
\hline ITGA2 & PARVA & PLAU & ARHGAP35 & LAMB2 \\
\hline HLA-E & SNX12 & CSNK2A2 & PRKCZ & ARAP1 \\
\hline FADD & RELB & GRM1 & CTNNA1 & PARD6A \\
\hline LAMB1 & CHMP4B & TNR & CHMPG & VCL \\
\hline WASF3 & PF4 & $\mathrm{CTTN}$ & JAM3 & PRKG1 \\
\hline ITGB5 & TGFB1 & EGF & $\mathrm{F} 2 \mathrm{R}$ & TLN1 \\
\hline RUFY1 & TUBB4A & ACTN1 & ZAK & MYLK \\
\hline MLLT4 & IGF1R & COLAA3 & VEGFC & LAMA5 \\
\hline LDLRAP1 & DNAIC6 & CCR7 & & \\
\hline CLDN2 & VPS37B & CLDN25 & CTSL1 & TAB1 \\
\hline ARPC1A & PRKACG & TUBB2B & SFTPA1 & MAGI2 \\
\hline PARD $6 G$ & TRAF3 & & & \\
\hline TUBB1 & CXCL5 & GNG11 & PPBP & ITGB3 \\
\hline MYL9 & GUCY1B3 & ITGA2B & DNM3 & GUCY1A3 \\
\hline SELP & THBS1 & CCL5 & & \\
\hline
\end{tabular}

C

High_ANA vs Low_ANA

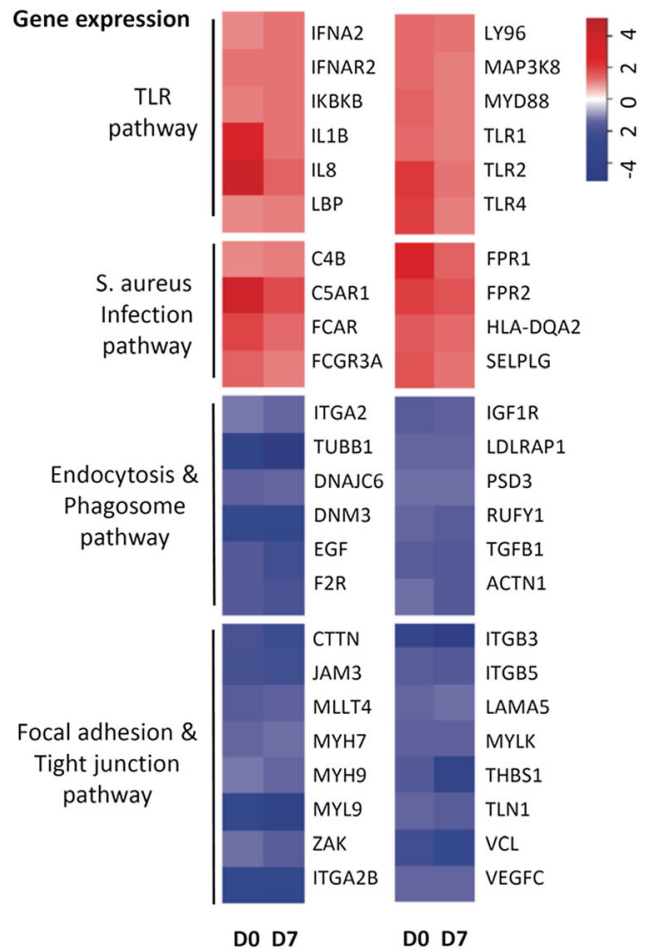

Fig. 2 (See legend on next page.) 
(See figure on previous page.)

Fig. 2 Gene expression profiles of purified B cells from HIV+ subjects with high ANA compared to low ANA production in response to influenza vaccination. The comparisons were analyzed by the ratios of gene expression in sorted total B cells from HIV+ high ANA $(n=5)$ vs low ANA $(n=9)$ subjects on D0 and D7 post-vaccination. a Heat map of fold changes in gene expression. Genes with similar patterns were grouped by clustering analysis (indicated by color bars on the left) and represented coherently changed genes in the clusters. b Representative immunological pathways enriched in coherently changed genes in HIV+ high ANA compared to low ANA subjects. c Expression of various gene encoding products in selected pathways showing increased (red) or decreased (blue) expression in HIV+ high ANA compared to low ANA subjects

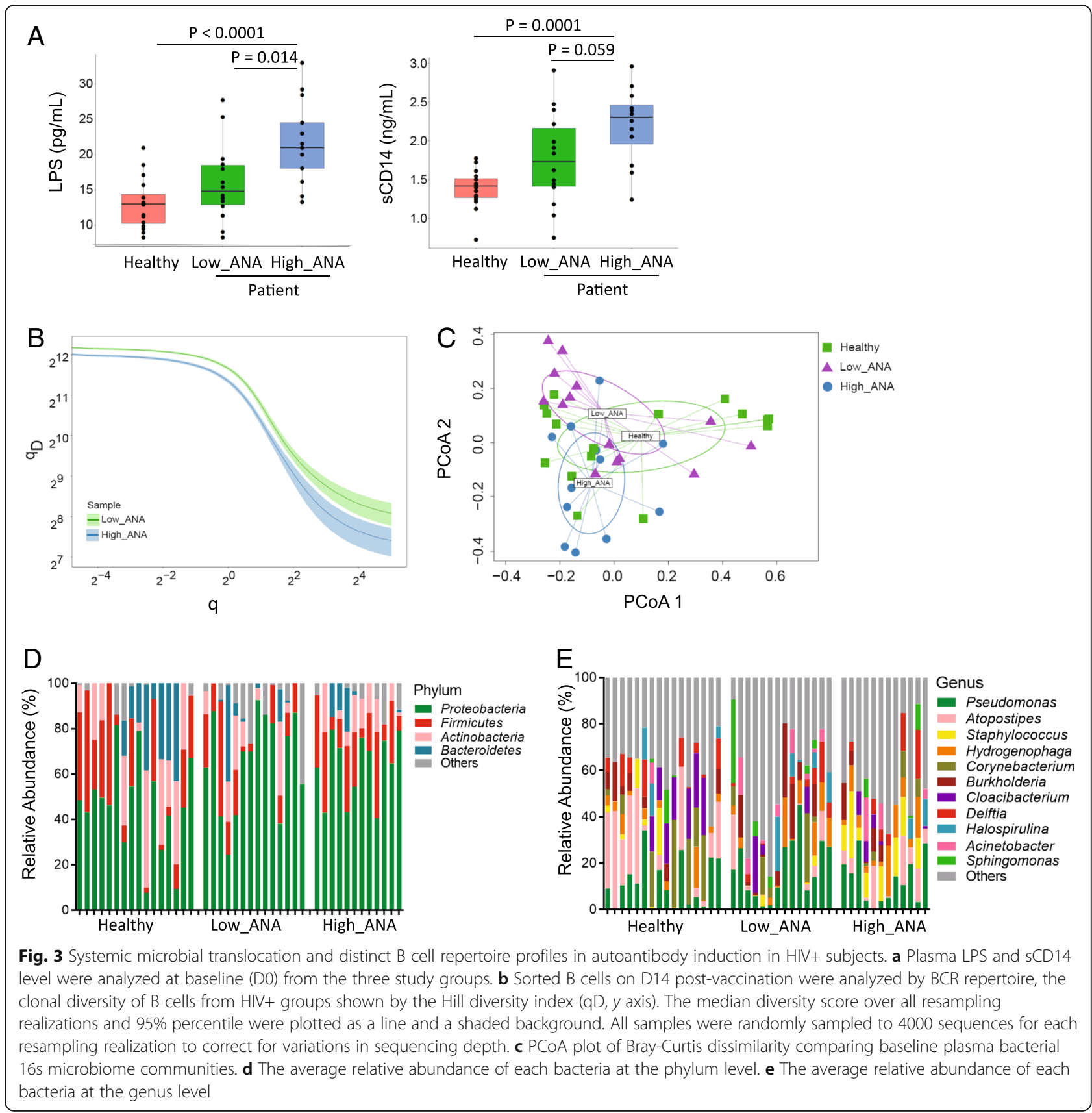


promoted clonal expansion compared to repertoires of HIV+ low ANA group. Highly diverse CDR3 region is thought to be the key determinant for antigen specificity and antibody recognition, and we found the median charges of CDR3 region in total IgA and IgG were increased in HIV+ high ANA group compared to low ANA group, whereas the median charges of CDR3 region in IgM were similar between the two HIV+ groups (Additional file 1: Figure S3D). These results were consistent with the previous study that autoreactive antibodies are more likely to have positively charged CDR3 region [20] and indicated that the $\mathrm{B}$ cells selection checkpoint in the GC from HIV+ high ANA group is abnormal $[1,36]$.

\section{Plasma microbiome in autoantibody induction in HIV+ subjects}

Studies on microbiome have shown that microbial species play a role in regulating host immune system [37]. In the current study, we are interested in systemic plasma microbiome and which microbial species affects autoantibody production in HIV. We detected and analyzed bacterial $16 \mathrm{~S}$ rDNA in plasma. To prevent the batch-to-batch variation, the samples from high ANA, low ANA, and healthy controls were sequencing at the same time. The OTUs detected in the water controls (Additional file 1: Table S3) were removed from results in the plasma samples. We analyzed Gini Simpson diversity index to compare diversity of overall microbial community and did not observe a significant difference between any two study groups ( $\alpha$-diversity, Additional file 1: Figure S3E). To compare compositional dissimilarity among the microbial communities ( $\beta$-diversity), the Bray-Curtis algorithm was applied to calculate distances between samples and shown in principal coordinate analysis (PCoA) plots. Again, we did not observe a significant difference in $\beta$-diversity between the two HIV+ groups (PERMANOVA, $P>0.05$ ) (Fig. 3c). We further analyzed plasma microbiome on different taxonomic levels. At the phylum-level, plasma microbiome was dominated by Proteobacteria (mean \pm SD, $44.9 \% \pm$ $22.0 \%$ vs $67.3 \% \pm 19.7 \%$ vs $56.3 \% \pm 21.0 \%$ ), Firmicutes $(22.0 \% \pm 17.8 \%$ vs $14.7 \% \pm 18.3 \%$ vs $21.7 \% \pm 13.8 \%)$, and Actinobacteria $(18.4 \% \pm 19.1 \%$ vs $6.0 \% \pm 9.2 \%$ vs $12.4 \% \pm$ $10.0 \%$ ) in healthy controls, HIV low ANA, and high ANA subjects, respectively (Fig. 3d). At the genus level, a significant increase in Staphylococcus was found in HIV+ high ANA group compared to low ANA group (Fig. 3e).

\section{Plasma translocation of Staphylococcus correlates with autoantibody production}

Given these results, we wondered if increased plasma level of Staphylococcus taxonomic group was related to autoantibody induction in HIV+ subjects. We compared Staphylococcus taxa between the two HIV+ groups and observed that HIV+ high ANA group had increased
Staphylococcus-associated taxa from the phylum to species level (Fig. 4a, b). Additionally, there were significant positive correlations between frequencies of plasma Staphylococci species and fold-changes of both ANA and anti-dsDNA IgG production in HIV+ subjects (Fig. 4c). These results indicate that Staphylococci may play a critical role in mediating autoantibody production in response to vaccination in ART-treated HIV+ subjects. Lipoteichoic acid (LTA, a TLR2 ligand) is the major constituent of cell walls from gram-positive bacteria. To verify the enrichment of Staphylococci in HIV+ high ANA group, we evaluated plasma level of antibody against LTA purified from Staphylococcus aureus and found plasma anti-LTA IgA but not IgG level was increased in HIV+ high ANA group compared to the other two groups (Fig. 4d). These results suggest that Staphylococcus infection or stimulation occurring mainly through the mucosal route [38] may play a role in systemic humoral immune perturbations in HIV disease.

\section{Staphylococcus induces autoantibody production, GC responses, and autoimmunity in mice}

To further evaluate whether Staphylococcus is responsible for the elevated autoimmune response found in some HIV + individuals, we tested the ability of Staphylococcus to induce autoimmunity in mice. Salmonella has been proved to induce autoantibodies [39] and was set as a positive control. Although Pseudomonas is the one of predominant taxa in HIV+ individuals, the high prescience of Pseudomonas had no correlation with autoantibody production. Therefore, Pseudomonas was chosen as the negative control for testing the ability of microbiome to induce autoantibody production. To test this, 6 -week-old healthy C57BL/6 mice were injected with phosphate buffered saline (PBS), heat-killed Salmonella typhimurium (HKST), heat-killed Pseudomonas aeruginosa (HKPA), or heat-killed Staphylococcus aureus (HKSA) twice a week for 4 weeks and then once a week for 8 weeks by intraperitoneal (i.p.) route. As expected, mice injected with PBS remained negative for autoantibodies. However, mice injected with HKST or HKSA produced robust anti-dsDNA autoantibodies, whereas mice injected with HKPA produced low levels of autoantibodies (Fig. 5a). Besides the autoantibody production, we observed the alveolar septa widened and inflammatory cell infiltration after injected with HKST or HKSA (Fig. 5b), and the disintegration of intestinal villi in response to HKST (Additional file 1: Figure S4A).

To investigate the effects of HKSA on adaptive immune cells in vivo, we measured B cell response in peripheral lymph nodes. Similar to HKST, HKSA induced significantly GC B cell differentiation and CD86 expression on GC B cells when compared with HKPA and PBS control (Fig. 5c-f), suggesting that HKSA and HKST promote GC responses in mice. Th17 cells are a pathogenic effector CD4 T cell lineage that plays critical roles in the pathogenesis of some 


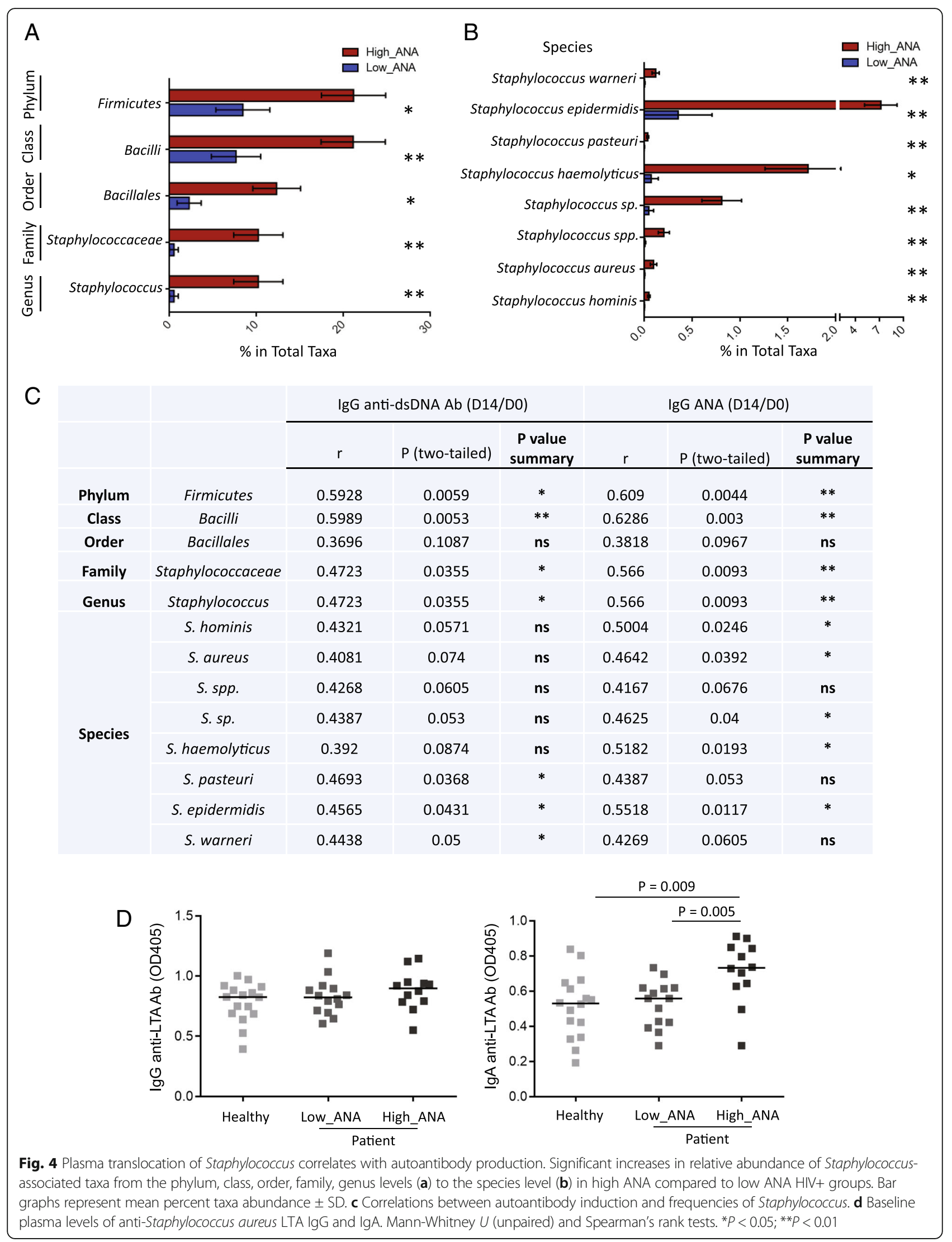




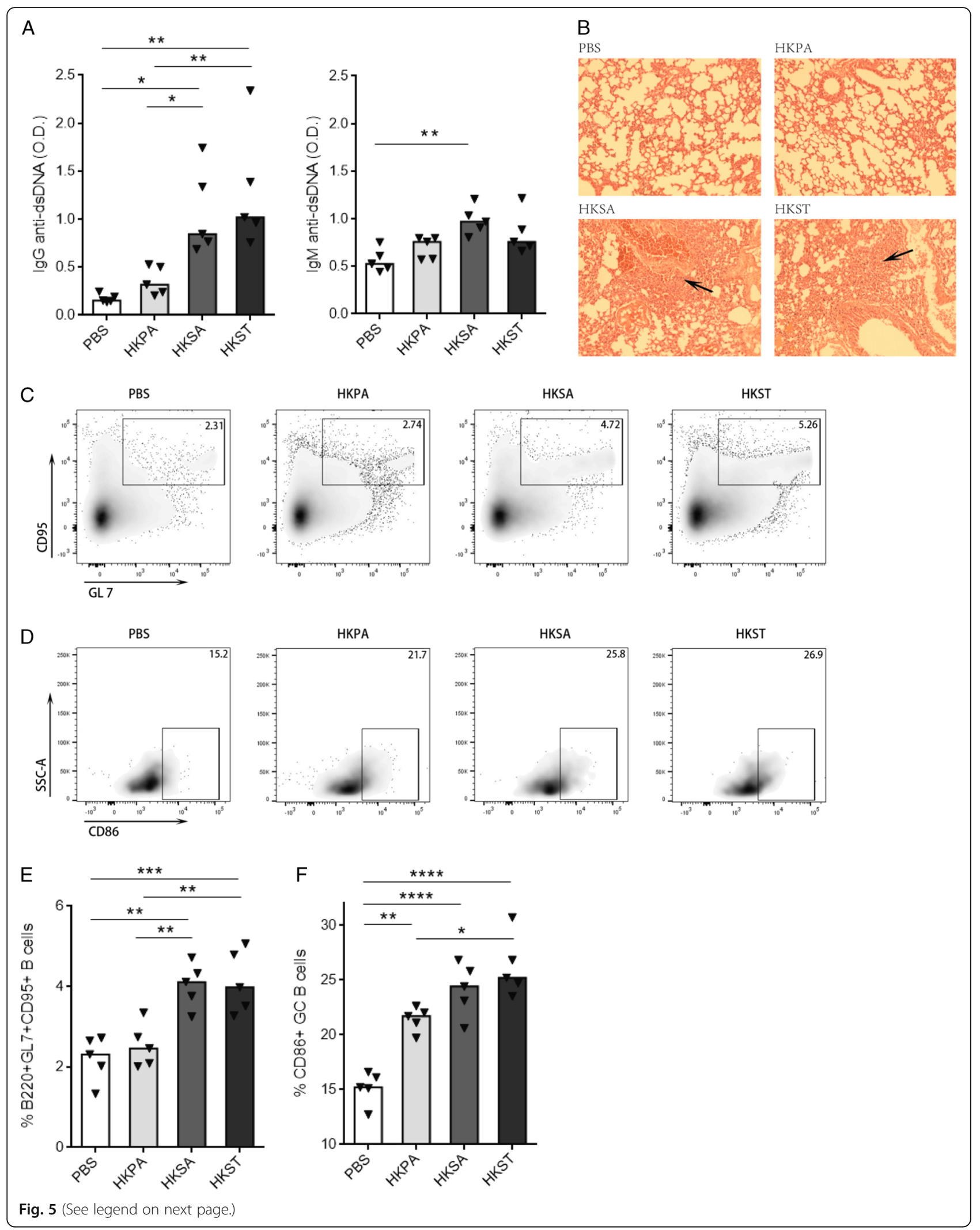


(See figure on previous page.)

Fig. 5 Staphylococcus induced autoantibody and autoimmunity. C57BL/6 mice were injected with PBS, or HKPA, or HKSA, or HKST twice a week for 4 weeks and following one time a week for 8 weeks by intraperitoneal (i.p.) route, $n=5$ per group. Figures were shown as scatter plot with median. a Anti-dsDNA autoantibodies were measured by ELISA in sera, and optical density (O.D.) indicates ELISA color change and the presence of anti-dsDNA autoantibodies. $\mathbf{b}$ The alveolar septa widened and inflammatory cell infiltration induced by HKSA or HKST were shown by H\&Estaining. c The percentages of germinal center cells (CD95+GL7+) from peripheral lymph nodes are shown in gated CD19+B220+ B cells. d The percentages of CD86+ cells are shown in gated germinal center B cells. e Proportions of GC B cells increased in the lymph nodes of HKSA and HKST groups compared to PBS or HKPA group. (F) The frequency of CD86+ GC B cells increased in the lymph nodes of mice after receiving HKST, HKSA, or HKPA. One-way ANOVA test, ${ }^{*} p<0.05,{ }^{* *} p<0.01,{ }^{* *} p<0.001,{ }^{* * * *} p<0.0001$

autoimmune diseases [40]. In view of the high level of anti-dsDNA antibodies in the response to HKST and HKSA, it was logical to ask whether Th17 would also show difference after being treated with HKSA or HKSA. Although the frequency of IL-17A-producing T cells in the spleen showed no difference after being treated with different bacteria (Additional file 1: Figure S4B), increased percentage of IL-22 + in the spleen memory CD4+ T cells was observed in mice being treated with HKSA when compared with those treated with HKPA (Additional file 1: Figure S4C). Intriguingly, compared with PBS control group, the CD25+CD69+ memory $\mathrm{CD} 4+\mathrm{T}$ cells and the IFN- $\gamma+\mathrm{CD} 4+\mathrm{T}$ cells were significantly increased in mice treated with HKPA but not in those treated with HKSA and HKST (Additional file 1: Figure S4D-4E). Those results indicated that Staphylococcus is capable to induce autoimmunity in mice through enhancing GC response and autoantibody production.

\section{Discussion}

Although both thymus-dependent (TD) and thymus-independent (TI) B cell responses are decreased in HIV-infected individuals prior to ART [41-43], most B cell defects in HIV infection are reversed after administration of ART [44]. An intriguing insight from this work was that the influenza antigen elicited autoantibodies in aviremic ART-treated HIV+ subjects. We further investigated the mechanism and cellular origins accounting for this observation.

Some autoantibodies can recognize both self-antigens and microbial epitopes after infection [45]. However, results from the competitive antigen binding experiment and mAbs showed that very limited number of autoantibodies displayed cross-reactivity. It indicated that the cellular origins of autoantibodies derived from the bystander $\mathrm{B}$ cells [46]. We further characterized gene expression patterns in B cells from HIV+ high ANA subjects compared to low ANA subjects by microarray and identified marked differences in genes related to microbial translocation, such as the TLR pathway, Staphylococcus aureus infection pathway, endocytosis and phagosome pathway, and focal adhesion and tight junction pathway (Fig. 2b, c). Tight junctions have been shown to play a role in regulating lung mucosal epithelial barrier function $[47,48]$, which relate to mucosal permeability and alveolar fluid clearance.
Subsequently, we found that both quantity and quality of plasma translocated bacterial products at baseline were associated with autoantibody production in response to vaccination in HIV+ subjects.

Microbiota plays a role in regulating host immune system development, homeostasis, and immunity against infection [49-51]. The microbiota composition in the system and mucosal surface in human is extremely variable and is related to host disease states $[52,53]$. The dominant species on the skin, in the oral cavity, or in the gastrointestinal tract differs significantly [54]. Systemic microbial translocation may be the key drivers for microbial product-mediated inflammation, innate immune activation, and immune perturbation $[55,56]$, but their roles in human health remain largely unknown. Plasma level of LPS, a marker of bacterial load [12], was increased in the high ANA HIV+ individuals compared to the other two study groups. The bacterial load in the plasma in the high ANA HIV+ individuals was far lower than the level in the plasma from patients with sepsis. Moreover, healthy individuals had lower LPS and sCD14 compared with HIV individuals. The plasma $16 \mathrm{~S}$ rDNA analysis showed that although there was no difference in the diversity of microbiota composition within each of the healthy controls and $\mathrm{HIV}+$ subjects, there was a significant increase in Staphylococcus-associated taxa from the phylum to the species level in HIV+ high ANA subjects compared to low ANA subjects. Notably, even after long-term ART treatment, skin or tissue infection of Staphylococcus aureus is still common in HIV-infected patients [57]. Staphylococcus aureus mainly colonizes on the skin and mucosa in human [58]; therefore, it is possible that enriched plasma Staphylococcus aureus found in some HIV+ subjects is derived from skin contamination during venipuncture, even the skin was wiped by alcohol prior to a blood draw. However, increased plasma level of IgA against LTA from Staphylococcus aureus was observed in $\mathrm{HIV}+$ subjects with high ANA group compared to controls (Fig. 4d), which cannot be explained by skin contamination during venipuncture. Moreover, there was a direct correlation between the enrichment of Staphylococcus-associated taxa and vaccine-induced autoantibody production. Additional experiments on C57BL/6 mice found that heat-killed Staphylococcus aureus directly induced autoantibodies. 
TLRs play critical roles in host immunities by recognizing and responding to microbial pathogens; they also mediate inflammatory responses and are involved in autoreactive antibody induction in autoimmune diseases [16-18, 59]. Microarray analysis of B cells has revealed that high ANA HIV+ subjects had upregulation of IL1B and $I L 23$ genes, which favor immune activation and are essential for disease development in several models of autoimmune disease [60]. TLRs/MyD88 signaling in B cells has been proposed to increase $\mathrm{B}$ cell migration to the GC dark zones [61] and contribute to their sustainment in the GC [62]. Meanwhile, TLRs may cooperate in conjunction with the $\mathrm{BCR}$ to play a function in the process of $\mathrm{B}$ cell negative selection. It has been suggested that alterations in BCR and TLR signaling pathways result in a defective central checkpoint and a failure to counter-selection developing autoreactive $\mathrm{B}$ cells in the bone marrow [63]. Moreover, B cell activation enhanced by $B C R / T L R$ dual signals can directly initiate humoral autoimmunity [34]. In our study, we found more focused and promoted clonal expansion of B cells and increased charges of CDR3 region in IgA and IgG from HIV+ high ANA group compared to repertoires of $\mathrm{HIV}+$ low ANA group. Moreover, treatment with inactivated Staphylococcus aureus and Salmonella typhimurium in C57BL/6 mice resulted in increased autoantibodies, B cells in the GC, and GC B cell activation. Our mice study showed that heat-inactivated Staphylococcus aureus promoted germinal center (GC) responses. Staphylococcus protein A (SpA) is a Staphylococcus surface protein [64]. SpA drives polyclonal B cell expansion, induces cell death, and enhances the short-lived extrafollicular response [64], and Staphylococcus lipoteichoic acid (LTA), on the surface of Staphylococcus, binds to TLR2 and activates TLR2 cell signaling pathway. TLRs can promote clonal expansion of autoreactive B cells after receiving BCR signals following antigen stimulation, which may provide the initial step in the generation autoantibodies [65].

In summary, our study has revealed that Staphylococcus can promote B cell activation and drive autoantibody production in ART-treated HIV+ subjects under immunological recovery. It may uncover a potential mechanism linking microbial translocation and autoimmunity.

\section{Additional file}

Additional file 1: Table S1. Clinical characteristics and baseline immune parameters. Table S2. Repertoire and reactivity of $31 \mathrm{mAbs}$ from dsDNA $+\mathrm{lgG}+\mathrm{B}$ cells in one HIV+ subject displayed substantial reactivity to dsDNA antigens. Table S3. The OUT in water control. Figure S1. Crossreactivity of purified IgG and IgM ANA to influenza vaccine antigens by competitive ELISA. Figure S2. Variation in gene expression. Figure S3. Systemic microbial translocation, B cell repertoire profiles, and plasma microbiome in autoantibody induction in HIV+ subjects. Figure S4. H\&E- stained sections of small intestine and T cells response from spleen of C57BL/6 mice after treated with PBS, HKPA, HKSA, or HKST. (PDF 3448 kb)

\section{Abbreviations}

ANA: Anti-nuclear antibody; ART: Antiretroviral therapy; BCR: B cells receptor; GC: Germinal center; HA: Influenza hemagglutinin; LPS: Lipopolysaccharides; mAbs: Monoclonal antibodies; TLR: Toll-like receptor

\section{Funding}

This work was supported by grants from the National Institutes of Allergy and Infectious Diseases: R01 Al091526 (Jiang), R01 Al128864 (Jiang), R01 CA213290 (Li), P30 Al027767 (Saag/Health), R01 AG045973 (Westerink), UL1TR001450, and R01 Al114380 (Wu), and the Medical Research Service at the Ralph H. Johnson VA Medical Center Merit grant VA CSRD MERIT (CX001211, Gilkeson), R01LM012517 (Alexander).

\section{Availability of data and materials}

Microarray data are available in GEO (Gene Expression Omnibus, https:// www.ncbi.n/m.nih.gov/geo/query/acc.cgi?acc=GSE101589) with the accession number GSE101589.

\section{Authors' contributions}

ZWL and WJ designed experiments. ZWL wrote the manuscript. ZWL, ML, and $\mathrm{MZ}$ analyzed the plasma microbiome data, gene expression microarray data, and B cells IGH repertoire data and contributed to the data interpretation and discussion. ZWL, ML, YW, LM, LZ, ZZ, SQ, ML, ZW, SW, and QL performed the experiments. EO, MW, HL, PJ, and DS contributed to the discussions. AW, XW, and $\mathrm{SH}$ provided and/or generated critical reagents and reviewed the manuscript. WJ, SH, XW, ZHL, and AA analyzed and interpreted the data and reviewed the manuscript.

\section{Ethics approval and consent to participate}

This study was approved by the Medical University of South Carolina (Pro00020606). All animal studies were approved by the Institutional Animal Care and Use Committee (IACUC) at the Medical University of South Carolina.

\section{Competing interests}

The authors declare that they have no competing interests.

\section{Publisher's Note}

Springer Nature remains neutral with regard to jurisdictional claims in published maps and institutional affiliations.

\section{Author details}

${ }^{1}$ Department of Microbiology and Immunology, Medical University of South Carolina, 173 Ashley Ave. BSB208D, Charleston, SC 29425, USA. ²Department of Gastroenterology, Oncology Bioinformatics Center, Minhang Hospital, Fudan University, Shanghai, China. ${ }^{3}$ Division of Infectious Diseases,

Department of Medicine, Medical University of South Carolina, Charleston, SC 29425, USA. ${ }^{4}$ Department of Medicine, Icahn School of Medicine at Mount Sinai, New York, NY 10029, USA. ${ }^{5}$ Cell Processing Section (CPS), Department of Transfusion Medicine, Clinical Center, NIH, Bethesda 20892, USA. ${ }^{6}$ Department of Immunology and Internal Medicine, University of Texas Southwestern Medical Center, 5323 Harry Hines Blvd, Dallas, TX 75390, USA. ${ }^{7}$ Sidra Medical and Research Center, Doha, Qatar. ${ }^{8}$ Aaron Diamond AIDS Research Center, The Rockefeller University, New York, NY 10016, USA. ${ }^{9}$ Division of Infectious Diseases, Department of Medicine, University of Alabama at Birmingham, Birmingham, AL 35294, USA. ${ }^{10}$ Program for Human Microbiome Research, Biomedical Informatics Center, Department of Public Health Sciences, Medical University of South Carolina, Charleston, SC 29425, USA.

Received: 10 May 2018 Accepted: 5 February 2019

Published online: 14 February 2019

\section{References}

1. Chan TD, Wood K, Hermes JR, Butt D, Jolly CJ, Basten A, Brink R. Elimination of germinal-center-derived self-reactive $B$ cells is governed by the location and concentration of self-antigen. Immunity. 2012;37:893-904. 
2. Zandman-Goddard G, Shoenfeld Y. HIV and autoimmunity. Autoimmun Rev. 2002;1:329-37.

3. Iordache L, Launay O, Bouchaud O, Jeantils V, Goujard C, Boue F, Cacoub P, Hanslik T, Mahr A, Lambotte O, et al. Autoimmune diseases in HIV-infected patients: 52 cases and literature review. Autoimmun Rev. 2014;13:850-7.

4. Lebrun D, Hentzien M, Cuzin L, Rey D, Joly V, Cotte L, Allavena C, Dellamonica P, Servettaz A, Bani-Sadr F. Epidemiology of autoimmune and inflammatory diseases in a French nationwide HIV cohort. Aids. 2017;31: 2159-66.

5. Guadalupe M, Sankaran S, George MD, Reay E, Verhoeven D, Shacklett BL, Flamm J, Wegelin J, Prindiville T, Dandekar S. Viral suppression and immune restoration in the gastrointestinal mucosa of human immunodeficiency virus type 1-infected patients initiating therapy during primary or chronic infection. J Virol. 2006:80:8236-47.

6. Cassol E, Malfeld S, Mahasha P, Van der Merwe S, Cassol S, Seebregts C, Alfano M, Poli G, Rossouw T. Persistent microbial translocation and immune activation in HIV-1-infected South Africans receiving combination antiretroviral therapy. J Infect Dis. 2010;202:723-33.

7. Luo Z, Li Z, Martin L, Wan Z, Meissner EG, Espinosa E, Wu H, Yu X, Fu P, Julia Westerink MA: Pathological Role of Anti-CD4 Antibodies in HIV-Infected Immunologic Nonresponders Receiving Virus-Suppressive Antiretroviral Therapy. J Infect Dis. 2017;216:82-91.

8. Perl A, Nagy G, Koncz A, Gergely P, Fernandez D, Doherty E, Telarico T, Bonilla E, Phillips PE. Molecular mimicry and immunomodulation by the HRES-1 endogenous retrovirus in SLE. Autoimmunity. 2008:41:287-97.

9. Nangaku M, Couser WG. Mechanisms of immune-deposit formation and the mediation of immune renal injury. Clin Exp Nephrol. 2005;9:183-91.

10. Rawlings DJ, Metzler G, Wray-Dutra M, Jackson SW: Altered B cell signalling in autoimmunity. Nat Rev Immunol. 2017;17:421-36.

11. Sanderson NS, Zimmermann M, Eilinger L, Gubser C, Schaeren-Wiemers N, Lindberg RL, Dougan SK, Ploegh HL, Kappos L, Derfuss T. Cocapture of cognate and bystander antigens can activate autoreactive B cells. Proc Natl Acad Sci. 2017;114:734-9.

12. Brenchley JM, Price DA, Schacker TW, Asher TE, Silvestri G, Rao S, Kazzaz Z, Bornstein E, Lambotte $\mathrm{O}$, Altmann $\mathrm{D}$, et al. Microbial translocation is a cause of systemic immune activation in chronic HIV infection. Nat Med. 2006;12: 1365-71.

13. Kamat A, Ancuta P, Blumberg RS, Gabuzda D. Serological markers for inflammatory bowel disease in AIDS patients with evidence of microbial translocation. PLoS One. 2010;5:e15533.

14. Lartigue A, Colliou N, Calbo S, Francois A, Jacquot S, Arnoult C, Tron F, Gilbert D, Musette P. Critical role of TLR2 and TLR4 in autoantibody production and glomerulonephritis in Ipr mutation-induced mouse lupus. J Immunol. 2009;183:6207-16.

15. Simchoni N, Cunningham-Rundles C. TLR7- and TLR9-responsive human B cells share phenotypic and genetic characteristics. J Immunol. 2015;194:3035-44.

16. Umiker BR, Andersson S, Fernandez L, Korgaokar P, Larbi A, Pilichowska M, Weinkauf CC, Wortis HH, Kearney JF, Imanishi-Kari T. Dosage of X-linked Tolllike receptor 8 determines gender differences in the development of systemic lupus erythematosus. Eur J Immunol. 2014;44:1503-16.

17. Wong CK, Wong PT, Tam LS, Li EK, Chen DP, Lam CW. Activation profile of Toll-like receptors of peripheral blood lymphocytes in patients with systemic lupus erythematosus. Clin Exp Immunol. 2010;159:11-22.

18. Thibault DL, Chu AD, Graham KL, Balboni I, Lee LY, Kohlmoos C, Landrigan A, Higgins JP, Tibshirani R, Utz PJ. IRF9 and STAT1 are required for lgG autoantibody production and B cell expression of TLR7 in mice. J Clin Invest. 2008:118:1417-26.

19. Wu X, Zhang Z, Schramm CA, Joyce MG, Kwon YD, Zhou T, Sheng Z, Zhang B, O'Dell S, McKee K, et al. Maturation and diversity of the VRCO1-antibody lineage over 15 years of chronic HIV-1 infection. Cell. 2015;161:470-85.

20. Wardemann H, Yurasov S, Schaefer A, Young JW, Meffre E, Nussenzweig MC. Predominant autoantibody production by early human B cell precursors. Science. 2003;301:1374-7.

21. Smith K, Garman L, Wrammert J, Zheng NY, Capra JD, Ahmed R, Wilson PC. Rapid generation of fully human monoclonal antibodies specific to a vaccinating antigen. Nat Protoc. 2009;4:372-84.

22. Bolstad BM, Irizarry RA, Åstrand M, Speed TP. A comparison of normalization methods for high density oligonucleotide array data based on variance and bias. Bioinformatics. 2003;19:185-93.

23. Vander Heiden JA, Yaari G, Uduman M, Stern JN, O'Connor KC, Hafler DA, Vigneault F, Kleinstein SH. PRESTO: a toolkit for processing high-throughput sequencing raw reads of lymphocyte receptor repertoires. Bioinformatics. 2014;30:1930-2.

24. Gupta NT, Vander Heiden JA, Uduman M, Gadala-Maria D, Yaari G, Kleinstein SH. Change-O: a toolkit for analyzing large-scale B cell immunoglobulin repertoire sequencing data. Bioinformatics. 2015;31:3356-8.

25. Vander Heiden JA, Stathopoulos P, Zhou JQ, Chen L, Gilbert TJ, Bolen CR, Barohn RJ, Dimachkie MM, Ciafaloni E, Broering TJ. Dysregulation of B cell repertoire formation in myasthenia gravis patients revealed through deep sequencing. J Immunol. 2017;198:1460-73.

26. Alekseyenko AV, Perez-Perez GI, De Souza A, Strober B, Gao Z, Bihan M, Li K, Methe BA, Blaser MJ. Community differentiation of the cutaneous microbiota in psoriasis. Microbiome. 2013;1:31.

27. Antico A, Platzgummer S, Bassetti D, Bizzaro N, Tozzoli R, Villalta D, Study Group on Autoimmune Diseases of the Italian Society of Laboratory M. Diagnosing systemic lupus erythematosus: new-generation immunoassays for measurement of anti-dsDNA antibodies are an effective alternative to the Farr technique and the Crithidia luciliae immunofluorescence test. Lupus. 2010;19:906-12.

28. Li QZ, Xie C, Wu T, Mackay M, Aranow C, Putterman C, Mohan C. Identification of autoantibody clusters that best predict lupus disease activity using glomerular proteome arrays. J Clin Invest. 2005;115:3428-39.

29. Koppensteiner H, Brack-Werner R, Schindler M. Macrophages and their relevance in Human Immunodeficiency Virus Type I infection. Retrovirology. 2012;9:1.

30. Torre D, Gennero L, Baccino F, Speranza F, Biondi G, Pugliese A. Impaired macrophage phagocytosis of apoptotic neutrophils in patients with human immunodeficiency virus type 1 infection. Clin Diagn Lab Immunol. 2002;9: 983-6.

31. Kawasaki TKT. Toll-like receptor signaling pathways. Front Immunol. 2014;25:461.

32. Sweet RA, Lee SK, Vinuesa CG. Developing connections amongst key cytokines and dysregulated germinal centers in autoimmunity. Curr Opin Immunol. 2012;24:658-64.

33. Choi J, Kim ST, Craft J. The pathogenesis of systemic lupus erythematosus-an update. Curr Opin Immunol. 2012;24:651-7.

34. Rawlings DJ, Schwartz MA, Jackson SW, Meyer-Bahlburg A. Integration of B cell responses through Toll-like receptors and antigen receptors. Nat Rev Immunol. 2012;12:282-94.

35. Hill MO. Diversity and evenness: a unifying notation and its consequences. Ecology. 1973;54:427-32.

36. Minegishi Y, Conley ME. Negative selection at the pre-BCR checkpoint elicited by human $\mu$ heavy chains with unusual CDR3 regions. Immunity. 2001;14:631-41.

37. Lelouvier B, Servant F, Païssé $S$, Brunet AC, Benyahya $S$, Serino $M$, Valle $C$, Ortiz MR, Puig J, Courtney M. Changes in blood microbiota profiles associated with liver fibrosis in obese patients: a pilot analysis. Hepatology. 2016;64:2015-27.

38. Holmgren J, Czerkinsky C. Mucosal immunity and vaccines. Nat Med. 2005; 11:S45-53.

39. Di Niro R, Lee S-J, Vander Heiden JA, Elsner RA, Trivedi N, Bannock JM, Gupta NT, Kleinstein SH, Vigneault F, Gilbert TJ. Salmonella infection drives promiscuous B cell activation followed by extrafollicular affinity maturation. Immunity. 2015;43:120-31.

40. Pfeifle R, Rothe T, Ipseiz N, Scherer HU, Culemann S, Harre U, Ackermann JA, Seefried M, Kleyer A, Uderhardt S. Regulation of autoantibody activity by the IL-23-TH17 axis determines the onset of autoimmune disease. Nat Immunol. 2017;18:104-13.

41. Hart M, Steel A, Clark SA, Moyle G, Nelson M, Henderson DC, Wilson R, Gotch F, Gazzard B, Kelleher P. Loss of discrete memory B cell subsets is associated with impaired immunization responses in HIV-1 infection and may be a risk factor for invasive pneumococcal disease. J Immunol. 2007; 178:8212-20.

42. De Milito A, Nilsson A, Titanji K, Thorstensson R, Reizenstein E, Narita M, Grutzmeier S, Sonnerborg A, Chiodi F. Mechanisms of hypergammaglobulinemia and impaired antigen-specific humoral immunity in HIV-1 infection. Blood. 2004;103:2180-6.

43. Titanji K, De Milito A, Cagigi A, Thorstensson R, Grutzmeier S, Atlas A, Hejdeman B, Kroon FP, Lopalco L, Nilsson A, Chiodi F. Loss of memory B cells impairs maintenance of long-term serologic memory during HIV-1 infection. Blood. 2006;108:1580-7.

44. Moir S, Fauci AS. B cells in HIV infection and disease. Nat Rev Immunol. 2009;9:235-45. 
45. Guilherme L, Kalil J, Cunningham M. Molecular mimicry in the autoimmune pathogenesis of rheumatic heart disease. Autoimmunity. 2006;39:31-9.

46. Bernasconi NL, Traggiai E, Lanzavecchia A. Maintenance of serological memory by polyclonal activation of human memory B cells. Science. 2002; 298:2199-202.

47. Furuse M, Hata M, Furuse K, Yoshida Y, Haratake A, Sugitani Y, Noda T, Kubo A, Tsukita S. Claudin-based tight junctions are crucial for the mammalian epidermal barrier: a lesson from claudin-1-deficient mice. J Cell Biol. 2002; 156:1099-111.

48. Rokkam D, LaFemina MJ, Lee JW, Matthay MA, Frank JA. Claudin-4 levels are associated with intact alveolar fluid clearance in human lungs. Am J Pathol. 2011;179:1081-7.

49. Atarashi K, Tanoue T, Shima T, Imaoka A, Kuwahara T, Momose Y, Cheng G, Yamasaki S, Saito T, Ohba Y. Induction of colonic regulatory T cells by indigenous Clostridium species. Science. 2011:331:337-41.

50. Abt MC, Osborne LC, Monticelli LA, Doering TA, Alenghat T, Sonnenberg GF, Paley MA, Antenus M, Williams KL, Erikson J. Commensal bacteria calibrate the activation threshold of innate antiviral immunity. Immunity. 2012;37:158-70.

51. Naik S, Bouladoux N, Wilhelm C, Molloy MJ, Salcedo R, Kastenmuller W, Deming C, Quinones M, Koo L, Conlan S. Compartmentalized control of skin immunity by resident commensals. Science. 2012;337:1115-9.

52. Gosmann C, Anahtar MN, Handley SA, Farcasanu M, Abu-Ali G, Bowman BA, Padavattan N, Desai C, Droit L, Moodley A. Lactobacillus-deficient cervicovaginal bacterial communities are associated with increased HIV acquisition in young South African women. Immunity. 2017:46:29-37.

53. Cho I, Blaser MJ. The human microbiome: at the interface of health and disease. Nat Rev Genet. 2012;13:260.

54. Lee YK, Mazmanian SK. Has the microbiota played a critical role in the evolution of the adaptive immune system? Science. 2010;330:1768-73.

55. Klatt NR, Funderburg NT, Brenchley JM. Microbial translocation, immune activation, and HIV disease. Trends Microbiol. 2013;21(1):6-13.

56. Karin $M$, Lawrence $T$, Nizet $V$. Innate immunity gone awry: linking microbial infections to chronic inflammation and cancer. Cell. 2006;124:823-35.

57. Liu CM, Osborne BJ, Hungate BA, Shahabi K, Huibner S, Lester R, Dwan MG, Kovacs C, Contente-Cuomo TL, Benko E, et al. The semen microbiome and its relationship with local immunology and viral load in HIV infection. PLoS Pathog. 2014;10:e1004262.

58. Williams R. Healthy carriage of Staphylococcus aureus: its prevalence and importance. Bacteriol Rev. 1963;27:56.

59. Iwasaki A, Medzhitov R. Regulation of adaptive immunity by the innate immune system. Science. 2010;327:291-5.

60. Harris KM, Fasano A, Mann DL. Cutting edge: IL-1 controls the IL-23 response induced by gliadin, the etiologic agent in celiac disease. J Immunol. 2008;181:4457-60.

61. Hwang I-Y, Park C, Harrison K, Kehrl JH. TLR4 signaling augments B lymphocyte migration and overcomes the restriction that limits access to germinal center dark zones. J Exp Med. 2009;206:2641-57.

62. Pasare C, Medzhitov R. Control of B-cell responses by Toll-like receptors. Nature. 2005:438:364-8.

63. Meffre $E$. The establishment of early B cell tolerance in humans: lessons from primary immunodeficiency diseases. Ann N Y Acad Sci. 2011;1246:1-10.

64. Keener AB, Thurlow LT, Kang S, Spidale NA, Clarke SH, Cunnion KM, Tisch R, Richardson AR, Vilen BJ. Staphylococcus aureus protein A disrupts immunity mediated by long-lived plasma cells. J Immunol. 2017;198:1263-73.

65. Herlands RA, Christensen SR, Sweet RA, Hershberg U, Shlomchik MJ. T cellindependent and toll-like receptor-dependent antigen-driven activation of autoreactive B cells. Immunity. 2008;29:249-60

\section{Ready to submit your research? Choose BMC and benefit from:}

- fast, convenient online submission

- thorough peer review by experienced researchers in your field

- rapid publication on acceptance

- support for research data, including large and complex data types

- gold Open Access which fosters wider collaboration and increased citations

- maximum visibility for your research: over $100 \mathrm{M}$ website views per year

At $\mathrm{BMC}$, research is always in progress.

Learn more biomedcentral.com/submissions 